\title{
Pemberdayaan Kader Posyandu Dalam Pencegahan Kanker Payudara Dengan Program SADARI Di Puskesmas Mamajang Kota Makassar
}

\author{
Sitti Rahmatia', Muhammad Basri², Baharuddin³, Rusni Mato ${ }^{4}$ \\ 1*. Poltekkes Kemenkes Makassar, Jl. Monumen Emmy Saelan III Tidung, Kota Makassar, Indonesia 90222 \\ 2. Poltekkes Kemenkes Makassar, Jl. Monumen Emmy Saelan III Tidung, Kota Makassar, Indonesia 90222 \\ 3. Poltekkes Kemenkes Makassar, Jl. Monumen Emmy Saelan III Tidung, Kota Makassar, Indonesia 90222 \\ 4. Poltekkes Kemenkes Makassar, Jl. Monumen Emmy Saelan III Tidung, Kota Makassar, Indonesia 90222 \\ *e-mail : rahmatiahakp@gmail.com
}

\begin{abstract}
Abstrak
Kanker payudara ditemukan secara dini dengan memeriksa Payudara Sendiri, pemeriksaan klinik, dan pemeriksaan mamografi. Deteksi dini dapat menekan angka kematian sebesar 25 - 30\% (Saryono,Dyah,2009). Upaya meurunkan angka kejadian dengan mengidentifikasi secara dini adanya kanker payudara, sehingga diharapkan dapat diobati dan berpeluang besar untuk sembuh. Pendidikan kesehatan merupakan salah satu metode untuk meningkatkan pengetahuan tentang kanker payudara yang dapat memotivasi wanita usia subur untuk melakukan deteksi dini kanker payudara. Tujuan dari Pengabdian Masyarakat ini adalah meningkatkan pengetahuan, kemampuan, dan motivasi kader posyandu dalam pencegahan kanker payudara dengan program Periksa Payudara Sendiri. Sasaran adalah kader posyandu dan wanita usia subur. Metode yang digunakan adalah pelatihan dan pendampingan kader (ceramah, tanyajawab, dan simulasi ) dengan program SADARI. Kegiatan dilaksanakan selama 2 hari pada tanggal 25 dan 26 Juli 2018 yang selanjutnya dilakukan penyuluhan ke masyarakat. Hasil yang didapatkan bahwa ke-5 Kader Posyandu tersebut sudah memahami dan termotivasi untuk malakukan pemeriksaan payudara sendiri (SADARI) Setelah 2 minggu pelaksanaan kegiatan pengabmas, dilaksanakan evaluasi hasil kegiatan dan didapatkan bahwa ada 5 orang wanita usia subur yang menderita kanker payudara dan 2 orang diantaranya sudah dilakukan biopsi/operasi. Hasil wawancara dengan Kader Posyandu tersebut dapat disimpulkan bahwa Wanita Usia Subur tersebut belum mengenal tentang pemeriksaan atau deteksi dini terhadap kanker payudara. Adapun rencana tindak lanjut yang kami ajukan bagi kegiatan ini yaitu Kegiatan serupa seharusnya dilaksanakan secara kontinu untuk meningkatkan pengetahuan, motivasi dan sikap para Kader Posyandu dalam pencegahan kanker payudara dengan teknik SADARI dan Diadakan kerjasama dengan Puskesmas dan Kader dalam pendampingan bagi Wanita Usia Subur dalam program SADARI
\end{abstract}

Kata Kunci : Pemberdayaan Kader Posyandu, Kanker Payudara, Program SADARI

\section{Pendahuluan}

Kanker payudara ditemukan secara dini dengan pemeriksaan SADARI, pemeriksaan klinik, dan pemeriksaan mamografi. Deteksi dini dapat menekan angka kematian sebesar 25 - 30\% (Saryono,Dyah,2009). Upaya deteksi dini kanker payudara adalah upaya untuk mendeteksi atau mengidentifikasi secara dini adanya kanker payudara, sehingga diharapkan dapat diobati dengan teknik yang dampak fisiknya kecil dan punya peluang besar untuk sembuh. Upaya ini sangat penting sebab apabila kanker payudara dapat dideteksi pada stadium dini dan diobati dengan tepat maka tingkat kesembuhannya cukup tinggi (80-90\%). Penemuan dini dimulai dengan peningkatan kesadaran masyarakat tentang perubahan bentuk atau adanya kelainan di payudara mereka sendiri.

Salah satu upaya yang dapat dilakukan oleh petugas kesehatan dalam memberi dan atau meningkatkan pengetahuan masyarakat tentang kanker payudara dan cara deteksi dini adalah dengan cara memberikan pendidikan kesehatan. Pendidikan kesehatan merupakan salah satu metode untuk meningkatkan pengetahuan tentang kanker payudara yang mempengaruhi motivasi wanita usia subur untuk melakukan deteksi dini kanker payudara.Meskipun informasi kanker payudara dan deteksi dini kanker payudara sudah banyak dikampanyekan, baik secara langsung maupun tidak langsung, namun masih banyak wanita usia subur di Wilayah Kerja Puskesmas Mamajang Kota Makassar kurang mengetahui dan memahami tentang kanker payudara dan cara pemeriksaan payudara sendiri (SADARI)

Dari data kesehatan di Puskesmas Mamajang Kota Makassar, didapatkan data bahwa ada 5 orang Wanita Usia Subur yang menderita tumor pada payudara.Dengan demikian, melalui pelatihan kepada Kader Posyandu dan Wanita Usia Subur di Wilayah kerja Puskesmas Mamjang Kota Makassar perlu mendapatkan pendidikan kesehatan secara langsung sehingga akan mempengaruhi motivasi mereka untuk melakukan pemeriksaan payudara sendiri (SADARI) 
Luaran yang diharapkandarikegiataniniadalahterlaksananyapendampingandan bimbingan para Kader Posyandu dalam Pencegahan Kanker Payudara Dengan Program SADARI .Dengandemikiansecara kontinyu dapat meningkatkan pengetahuan, motivasi dan sikap para Kader Posyandu dalam pencegahan kanker payudara dengan teknik SADARI.

\section{Metode}

Pengabdian Masyarakat ini dilaksanakan mulai bulan Mei sampai dengan Juli bertempat di Posyandu Kenanga Wilayah Kerja Puskesmas Mamajang KotaMakassar

Metode pelaksanaan kegiatan pengabdian masyarakat ini adalah dengan melakukan pelatihaan dan pendampingan kader. Setelah diberi pelatihan, selanjutnya kader dibimbing untuk menerapkan hasil pelatihan dalam rangka meningkatkan pengetahuan, kemampuan dan motivasi dalam kegiatan pencegahan kanker payudara dengan program pemeriksaan payudara sendiri (SADARI) di Wilayah Kerja Puskesmas Mamajang Kota Makassar.Jumlah Kader posyandu yang terlibat dalam kegiataninisebanyak 6 orang, dengandidamingi 2 orang petugas/ bidandariPuskesmasMamajang.Kegiatan dimulai dari tahapan perencanaan/ persiapan yang diawali dengan survey /penjajakanlokasi, identifikasi masalah dan penentuan sasaran dengan berkoordinasi para Kader Posyandu untuk menyepakati kembali tujuan,waktu dan tempat dan peserta dari pelaksanaan kegiatan.Setelah mendapat izin dari Kepala Puskesmas, selanjutnya dilakukan kegiatan pelatihan yang terdiri dari dua sesi yaitu pemberian penjelasan dan memotivasi kader posyandu agar mau melakukan pencegahan kanker payudara dengan program SADARI oleh Tim Pengandian Masyarakat, kemudian dalam kurung lebih 15 menit dilanjutkan sesi kedua menitikberatkan pada kemampuan melaksanakan kegiatan tentang pencegahan kanker payudara dengan program SADARI yang dilakukandengan teknik simulasi agar para kader mendapatkan pengalaman secara langsung.

\section{Hasil}

Kegiatan pengabdian masayarakat di laksanakan setelah mendapat izin/ rekomendasi dari Dinas Kesehatan Kota Makassar. Selanjutnya surat izin atau rekomendasi Dinas Kesehatan Kota di sampaikan ke Kepala Puskesmas Mamajang Makassar, untuk menyepakati ,waktu dan tempat dan peserta dari pelaksanaan kegiatan pengabmas. Kegiatan ini mendapat dukungan positif dari masyarakat setempat maupun dari pihak Puskesmas.Pelasanaan kegiatan ini dilakukan dengan 2 tahap, yaitu tahap persiapan dimulai survey/ penjajakanlokasi dan sasaran, serta tahap pelaksanaan pelatihan.Jumlah kader yang diundang pelatihan dari masing-msing posyandu sebanyak 6 orang yang didampingi dengan 2 orang bidan Puskesmas namun peserta yang sempat hadir sebanyak 20 orang wanita usia subur.Materi pelatihan berupa Pengenalan Penyakit Kanker Payudara, Deteksi Dini Kanker Payudara dengan Tehnik SADARI. Adapun tujuan dari pelaksanaan ini pengetahuan tentang kanker payudara yang diawali dengan pre test dan pemberian materi terkait kanker payudara dan diakhiri dengan post test sebagai evaluasi kegiatan pemberian materi. Kegiatan penyuluhan dilakukan dengan metode ceramah dan demonstrasi. Metode ceramah dilakukan untuk menyampaikan berbagai informasi umum mengenai pengenalan tentang Kanker Payudara khususnya pemeriksaan payudara sendiri (SADARI).

Berdasarkan kegiatan tersebut diatas, maka Tim Pengabdian Masyarakat mendapatkan hasil sebagai berikut :

Tabel 1 Distribusi hasil Pre test dan post test berdasarkan Pengetahuan Kader Posyandu Dalam Pencegahan Kanker Payudara Dengan Program SADARI di Wilayah Kerja Puskesmas Mamajang Kota Makassar.

\begin{tabular}{|c|c|c|c|c|c|c|}
\hline \multirow{3}{*}{ Test } & \multicolumn{3}{|c|}{$\begin{array}{c}\text { Pengetahuan Kader Dalam } \\
\text { Pencegahan Kanker Payudara Dengan } \\
\text { Program SADARI }\end{array}$} & \multicolumn{3}{|c|}{ Total } \\
\cline { 2 - 6 } & \multicolumn{3}{|c|}{ Baik } & \multicolumn{2}{c|}{ Kurang } & \multicolumn{2}{c|}{} \\
\cline { 2 - 7 } & $\mathrm{n}$ & $\%$ & $\mathrm{n}$ & $\%$ & $\mathrm{n}$ & $\%$ \\
\hline Pre & 5 & 41,6 & 7 & 58,3 & 12 & 100 \\
\hline Post & 12 & 100 & 0 & 0 & 12 & 100 \\
\hline
\end{tabular}

Berdasarkan Tabel 1 diatas menunjukkan pengetahuan tentang pencegahan kanker payudara dengan Teknik SADARI di Puskesmas Mamajang Kota Makassar saat pre test relative rendah.dan pengetahuan kader dengan kategori baik, dari $58,3 \%$ menjadi $100 \%$ pada saat post test. 
Tabel 2 Distribusi hasil Pretest dan posttest berdasarkan kemampuan Kader Dalam upaya Pencegahan Kanker Payudara Dengan program SADARIdi wilayah kerja Puskesmas Mamajang Kota Makassar.

\begin{tabular}{|c|c|c|c|c|c|c|}
\hline \multirow{3}{*}{ Test } & \multicolumn{3}{|c|}{$\begin{array}{c}\text { Pengetahuan Kader Dalam } \\
\text { Pencegahan Kanker Payudara Dengan } \\
\text { Program SADARI }\end{array}$} & \multicolumn{2}{c|}{ Total } \\
\cline { 2 - 7 } & \multicolumn{3}{|c|}{ Baik } & \multicolumn{2}{c|}{ Kurang } & \multicolumn{2}{c|}{} \\
\cline { 2 - 7 } & $\mathrm{n}$ & $\%$ & $\mathrm{n}$ & $\%$ & $\mathrm{n}$ & $\%$ \\
\hline Pre & 5 & 25 & 7 & 75 & 12 & 100 \\
\hline Post & 12 & 100 & 0 & 0 & 12 & 100 \\
\hline
\end{tabular}

Berdasarkan tabel 2 diatas menunjukkan terjadi peningkatan kemampuan Kader Dalam upaya Pencegahan Kanker Payudara Dengan program SADARI saat pre test, kemampuan kader dengan kategori baik, dari $25 \%$ menjadi $100 \%$ pada saat post test (5 orang). Dan saat pre test pengetahuan dengan kategori kurang, sebesar $75 \%$ ( 7 orang )

Tabel 3 Distribusi hasil Pretest dan posttest berdasarkan Motivasi Kader Dalam upaya Pencegahan Kanker Payudara Dengan program SADARIdi wilayah kerja Puskesmas Mamajang Kota Makassar.

\begin{tabular}{|c|c|c|c|c|c|c|}
\hline \multirow{3}{*}{ Test } & \multicolumn{3}{|c|}{$\begin{array}{c}\text { Motivasi Kader dalam Upaya } \\
\text { Pencegahan Kanker Payudara dengan } \\
\text { Program SADARI }\end{array}$} & \multicolumn{2}{|c|}{ Total } \\
\cline { 2 - 5 } & \multicolumn{3}{|c|}{ Baik } & \multicolumn{2}{c|}{ Kurang } & \multicolumn{2}{c|}{} \\
\cline { 2 - 7 } & $\mathrm{n}$ & $\%$ & $\mathrm{n}$ & $\%$ & $\mathrm{n}$ & $\%$ \\
\hline Pre & 5 & 25 & 7 & 75 & 12 & 100 \\
\hline Post & 12 & 100 & 0 & 0 & 12 & 100 \\
\hline
\end{tabular}

Berdasarkan Tabel 3 menunjukkan terjadi peningkatan motivasi Kader dalam upaya pencegahan kanker payudara dengan program SADARI saat pre test, motivasi kader dengan kategori baik, dari $25 \%$ menjadi $100 \%$ pada saat post test (5 orang). Dan saat pre test pengetahuan dengan kategori kurang, sebesar 75\%( 7 orang ).

\section{Pembahasan}

Hasil survey pendahuluan dan wawancara dengan Kader Posyandu di Wilayah kerja Puskesmas Mamajang Kota Makassar terlihat bahwa ada 5 orang wanita usia subur yang menderita kanker payudara dan 2 orang diantaranya sudah dilakukan biopsi/operasi. Hasil wawancara dengan Kader Posyandu tersebut dapat disimpulkan bahwa Wanita Usia Subur tersebut belum mengenal tentang pemeriksaan atau deteksi dini terhadap kanker payudara. Selain itu mereka menyatakan bahwa ingin sekali mengetahui cara deteksi dini kanker payudara dengan program SADARI. Bahkan sebagian Wanita Usia Subur ini mengenal kanker payudara adalah penyakit keturunan. Lebih lanjut, Kader Posyandu mengatakan bahwa masih ada wanita usia subur diwilayah ini yang menderita kanker payudara namun belum mau terbuka dan cenderung tidak memeriksakan diri ke Puskesmas. Olehnya itu Tim Pengabdian Manyarakat bersama sama dengan Kader Posyandu menawarkan kegiatan Pemeriksaan Payudara Sendiri (SADARI)kepada Wanita Usia Subur untuk dilaksanakan pelatihan pemeriksaan payudara sendiri (SADARI) dan setelah itu dilanjutkan dengan penyuluhan tentang Kanker Payudara dan cara pencegahannya dengan program SADARI.

Kegiatan penyuluhan dilakukan dengan metode ceramah dan demonstrasi. Metode ceramah dilakukan untuk menyampaikan berbagai informasi umum mengenai pengenalan tentang Kanker Payudara khususnya pemeriksaan payudara sendiri (SADARI). Pada kesempatan ini disampaikan bahwa upaya pencegahan terjadinya kanker payudara dapat dicegah sedini mungkin dengan melakukan Periksa Payudara Sendiri (SADARI) .Setelah itu dilaksanakan demonstrasi tentang hal-hal praktis dalam melakukan Periksa Payudara Sendiri (SADARI).

Sebagai tindak lanjut dari penyuluhan ini, dan untuk melihat manfaat pelatihan, maka dilakukan evaluasi pendampingan Kader dalam mensosialisasikan pencegahan secara dini kanker payudara dengan metode SADARI.

\section{Kesimpulan}

Dari hasil kegiatan penyuluhan pendampingan Kader Posyandu dalam pencegahan kanker payudara dengan program SADARI, diharapkan adanya peningkatan pengetahuan, kemampuan, motivasipara Kader Posyandu dalam pencegahan secara dini kanker payudara dengan program SADARI dan khususnya Wanita Usia Subu mau memanfaatkan Puskesmas untuk memeriksakan masalah kessehatannya. 


\section{Saran}

A. Perlu adanya tindak lanjut dari para Kader Posyandu untuk terus berupaya menggalakkan SADARI khususnya pada Wanita Usia subur yang beresiko terkena kanker payudara.

B. Perlu adanya pemberdayaan Kader Posyandu dalam pencegahan kanker payudara dengan program SADARI

C. Meningkatkan pembinaan bagi petugas kesehatan dan bidan di Wilayah kerja Puskesmas Mamajang Kota Makassar agar senantiasa memotivasi Kader Posyandu terus berupaya menggalakkan SADARI khususnya pada Wanita Usia subur yang beresiko terkena kanker payudara.

\section{Daftar Pustaka}

Bahiyatun. 2009. Buku Ajar Asuhan Kebidanan Nifas Normal. EGC, Jakarta.

Cunningham. 2006.Obstetri Williams.Vol, 1. Edisi 21. EGC, Jakarta.

Harun Yahya. 2009. Manfaat ASI Dan ASI eksklusif(http://www.harunyahya.com, diakses 17 Maret 2010.

Hidayat Alimul Aziz. 2007. Metode Penelitian Keperawatan dan TeknikAnalisa Data. Salemba Medica, Jakarta.

Farrer, Helen. 2001. Perawatan Maternitas. Edisi 2. EGC. Jakarta.

Luwia, S, Mellissa. 2003. Problematik \& Perawatan Payudara Kesehatan dan Kecantikan. Kawan Pustaka. Jakarta.

Nanix. 2009. Perawatan Payudara Pada Ibu Hamil Dan Ibu Nifas. (http://www.kesehatan.com, diakses 9 Maret 2010).

Notoatmodjo, Dr. Soekidjo. 2005. Metodologi Penelitian Kesehatan. PT. Rineka Cipta, Jakarta.

Nursalam. 2003. Konsep Dan Penerapan Metodologi Penelitian Ilmu Keperawatan. Salemba Medika, Jakarta.

Perkumpulan Perinatologi Indonesia, 2007, Manajemen Laktasi : Menuju Persalinan Aman dan Bayi Lahir Sehat.

Puskesmas Lancirang. 2010. Medical Record. Puskesmas Lancirang Sidrap.

Ratihrochmat, 2008, Perawatan Masa Nifas, (http://wordpress.com, diakses 9 maret 2010).

Rini Mulyani. 2009. Pengaruh Metode Demontrasi Perawatan Payudara Terhadap Kelancaran Pengeluaran ASI Pada Ibu Nifas Di Ruang Nifas RS. Siti Fatimah Makassar. Skripsi tidak diterbitkan. Makassar : STIKES Nani Hasanuddin.

Saleha,Sitti. 2009. Asuhan Kebidanan Pada Masa Nifas. Salemba Medika, Jakarta.

Samhadi. 2008. Anatomi dan Fisiologi Payudara. (http://www.lusa.web.id, diakses 9 Maret 2010).

Saryono. 2008. Perawatan Payudara. Mitra Cendekia. Jogjakarta.

Suherni. 2009. Perawatan Masa Nifas. Fitramaya. Yogyakarta.

Tim Penyusun. 2010. Pedoman Penulisan Skripsi. Edisi 6. Stikes Nani Hasanuddin, Makassar.

Wiknjosastro, Hanifa. 2007. Ilmu Kebidanan. Edisi 3. Yayasan Bina Pustaka Sarwono Prawirohardjo. Jakarta 